\title{
Audit of paediatric cardiac services in South Africa
}

\author{
E.G.M. Hoosen", A.M. Cilliers", C.T. Hugo-Hamman", \\ S.C. Brown ${ }^{\ddagger}$, J.R. Harrisbergt, F.F.Takawira ${ }^{\S}$, \\ K. Govendrageloo†, J. Lawrenson ${ }^{\ddagger}$ and J. Hewitson ${ }^{* *}$ \\ * Paediatric Cardiology, Inkosi Albert Luthuli Central Hospital, University \\ of KwaZulu-Natal, Durban \\ \# Division of Paediatric Cardiology, C.H. Baragwanath Hospital, \\ University of Witwatersrand, Johannesburg \\ + Paediatric cardiologist, Constantiaberg Medi Clinic and lecturer, \\ University of Stellenbosch, Cape Town \\ * Department of Paediatric Cardiology, Universitas Academic Hospital \\ University of the Free State, Bloemfontein \\ † Paediatric cardiologist, Sunninghill Hospital, Johannesburg \\ $\S$ Department of Paediatric Cardiology, Steve Biko Academic Hospital \\ and University of Pretoria \\ ₹ Paediatric Cardiology Services of the Western Cape, Red Cross \\ Children's Hospital and Tygerberg Hospitals University of Cape Town \\ and Stellenbosch University, Cape Town \\ ${ }^{* *}$ Cardiothoracic surgeon: Red Cross Children's Hospital, University of \\ Cape Town
}

Address for correspondence:

Dr E.G.M. Hoosen

Paediatric Cardiology

Inkosi Albert Luthuli Central Hospital

800 Bellair Road

Durban

4001

South Africa

Email:

ebrahimhoo@ialch.co.za

\section{INTRODUCTION}

There is an increasing demand on the services provided by paediatric cardiologists worldwide. The type of care includes the investigation and management of both children and adults with congenital heart disease. Further patient support includes percutaneous interventional procedures, pre-operative assessment of complex congenital heart lesions and post-operative followup. An additional source of workload is the echocardiographic

\section{ABSTRACT}

Objective: To evaluate paediatric cardiac services in South Africa with respect to referral base, services provided and human resources.

Study design: A descriptive study design was used. An audit of the referral base, personnel and activity of paediatric cardiac units throughout South Africa was conducted by means of a questionnaire. A specialist from each centre was asked to provide the relevant data. Where accurate data was not available, estimates were provided by practitioners within each centre.

Results: All identified units participated in the audit. Three were private sector units while the other five were primarily public sector units. Twenty four paediatric cardiologists, equally distributed between public and private sector units, were practicing in the country as at end 2008 , with a further eight paediatricians undergoing training in paediatric cardiology. This is significantly less than the 88 paediatric cardiologists required for the population of South Africa. Eight paediatric cardiac surgeons were operating predominantly on children in public hospitals and five in private institutions.

An estimated 1370 operations for congenital heart disease were performed over a one year period, with $\mathbf{8 0 0}$ of these in the public sector. Extrapolating from accepted estimates of congenital heart disease incidence, this represents conservatively, less that $40 \%$ of operations required for the population. Additionally, only $26 \%$ of the estimated $1 / 4$ simple transposition of great arteries born annually were operated on, indicating serious deficiencies in the ability to adequately detect and intervene in serious congenital heart disease presenting in the neonatal period.

Conclusion: The infrastructure and resources to detect and manage heart disease in children in South Africa, particularly within the public sector, are grossly inadequate.

SAHeart 201 0; 7:4-9

confirmation of congenital heart lesions in the foetus, the care of children with acquired heart disease and the investigation of innocent murmurs of childhood. There is a local perception that the demand for these services far exceeds the available skills in South Africa. In addition to the cardiological needs of our population, the need for surgery for children with heart lesions appears 
to be far greater than the ability of at least the State health services to supply.

\section{BACKGROUND}

Ideally each centre providing paediatric cardiac services should have a minimum of I paediatric cardiologist per 0.5 million of the population served, ${ }^{(1)}$ indicating the need for 88 paediatric cardiologists to attend to the need of the 44 million people of South Africa. Any centre providing open-heart surgery on young children should have 2 surgeons each doing at least 40-50 open-heart procedures per year. ${ }^{(1)}$

The incidence of congenital heart disease is just under $0.8 \%$ of all live births whereas the incidence of serious congenital heart disease varies between 4-6/I 000 live births. While there are very few studies in developing countries, it is expected that the incidence is no different in South Africa. According to population statistics there were I 380, 497 live births registered in South Africa in 2005.(2) Based on these statistics the incidence of children with congenital heart disease born every year is approximately 1 I 000, with 50\% needing invasive diagnostic procedures and 40\% needing open heart surgery every year. ${ }^{(3)}$

Further, there remains in South Africa, as in the rest of Africa, a significant burden of rheumatic fever and rheumatic heart disease (RHD). In Mozambique, the prevalence of RHD has been shown to be as high as 30.4 per 1000 in school children aged between 6 and 17 years of age. ${ }^{(4)}$ It is likely that in parts of South Africa a similar prevalence would be found. This concern was the impetus for the Ist All Africa Workshop on Rheumatic Fever (RF) and Rheumatic Heart Disease (RHD) held at Champagne Sports Resort in the Drakensberg, South Africa on 15 - 16 October 2005. At this meeting "The Drakensberg Declaration on the Control of Rheumatic Fever and Rheumatic Heart Disease in Africa" was signed by delegates involved and a commitment to the prevention of rheumatic fever and rheumatic heart disease was made.(5)

Paediatric cardiac services are also increasingly called upon to assess children with innocent murmurs, present at some stage in $40 \%$ of children of school going age.(1)
Other areas of increasing service demand are prenatal evaluation of foetuses suspected to have cardiac lesions, the assessment of preterm neonates with suspected patent ductus arteriosus, and screening for cardiac lesions in neonates with other congenital abnormalities.

In the current era, at least $85 \%$ of children born with congenital heart disease should reach adult life if treated appropriately. ${ }^{(6)}$ Appropriate development of services for this group of patients with a good potential long term outcome should therefore be a priority.

\section{Paediatric cardiac services in South Africa at present}

In the public sector, five major centres offer comprehensive paediatric cardiac services in South Africa, namely:

I. Johannesburg complex - made up of Chris Hani Baragwanath, Charlotte Maxeke (previously Johannesburg General) and Rahima Moosa (previously Coronation) Hospitals - provide services to South Gauteng, part of the North West Province and part of Mpumulanga province.

2. Steve Biko Academic Hospital, Pretoria - covers North Gauteng, part of North West Province, part of Mpumulanga and the whole of Limpopo province.

3. Universitas Academic Hospital - Bloemfontein - covers Free State, most of Northern Cape and Lesotho.

4. Inkosi Albert Luthuli Central Hospital, Durban - whole of KwaZulu-Natal and Tambo District of Eastern Cape.

5. Western Cape paediatric cardiac services - consists of Red Cross and Tygerberg Hospitals. Covers Western Cape, parts of Northern and Eastern Cape.

The private sector paediatric cardiac services are largely provided at three hospitals in South Africa:

I. Sunninghill Hospital in Johannesburg

2. Christiaan Barnard Memorial Hospital in Cape Town

3. Unitas Hospital, Pretoria

These private institutions provide comprehensive services to the approximately $15 \%$ of the population that have access to medical aid from throughout the country as well as a relatively small number of patients referred from surrounding countries. The unit 
in Bloemfontein provides services to both the public and private sector. The recently established "Walter Sisulu Paediatric Cardiac Centre for Africa" (WSPCCA) based at Sunninghill Hospital provides some cardiac care using donor funding to patients from other parts of Africa as well as uninsured patients from South Africa.

Increasing concern has been expressed amongst paediatric cardiac health practitioners that even though there is under-diagnosis of heart disease, the needs of children with documented heart disease are not being adequately addressed, and that paediatric cardiac services in most public sector centres are overwhelmed. To this end a Workshop on Paediatric Cardiac Services was held on the 25th November 2007 preceding the South African Heart Association Congress. Among the resolutions of this meeting was that an audit of paediatric cardiac services in the country as well as a plan for a viable and sustainable service for the future should be made and documented.

\section{STUDY DESIGN}

The study is an audit of each unit's referral base, activities and personnel. Ethics approval was obtained from the University of KwaZulu-Natal Biomedical Research Ethics Committee. Data from each public service unit was obtained by means of a questionnaire completed by the head of each unit of a recognised paediatric cardiology and cardiothoracic service within South Africa with the consent of the relevant hospital authority. In the case of private institutions, a paediatric cardiologist or cardiothoracic surgeon from each hospital was given the responsibility of collating the data, or where necessary, data was collated from representatives of each practice within the hospital. Where accurate records were not available, estimates of patient numbers and operations performed were provided by paediatric cardiologists or paediatric surgeons from the relevant centres. The patient data was for patients seen over a one year period (2006) while in terms of staffing and infrastructure the most current data was used (2008).

\section{RESULTS}

The major centres and the total population sizes served (including medical aid patients) are reflected in Tables $I$ and 2 . Within the public sector, the $10-15 \%$ of the populations that are on medical aid are usually cared for in private sector hospitals with the exception of Bloemfontein, where private and public services are provided within the same unit. In addition, patients from Lesotho are referred to Bloemfontein by governmental agreement. The staff complements for different units are demonstrated in Table 3. By the end of 2008, 24 paediatric cardiologists were practising in the country, with almost equal distribution between the public and private sector. A further eight are in training. The distribution of the 13 surgeons doing a significant volume of congenital heart surgery is also demonstrated. There is, as yet, no formal training programme for congenital heart surgery in the country. The numbers and distribution of anaesthetists are also tabulated. Postoperative intensive care facilities impact greatly on the service offered. The number of intensive care beds available to each unit and the team providing the primary care is shown in Table 4. The core services performed in terms of patients seen, echocardiography, cardiac catheterisation and surgery are tabulated in tables 5-7. The waiting list indicates the number of patients requiring surgery whose operations are delayed due to lack of capacity at the unit. The number of Simple Transposition of Great

TABLE I: Public centre paediatric cardiac units in South Africa and the population covered by each unit

\begin{tabular}{|l|l|l}
\hline \hline Unit & Coverage area & Estimated population served* \\
\hline Johannesburg complex & South Gauteng / part North West province / part Mpumulanga & $\sim 10.2 \mathrm{~m}$ \\
\hline Pretoria (Steve Biko Academic Hospital) & North Gauteng / part North West province / Mpumulanga (I/2), Limpopo & $\sim 9 \mathrm{~m}$ \\
\hline Bloemfontein (Universitas Academic Hospital) & Free State, Northern Cape and Lesotho & $4.1 \mathrm{~m}(+$ Lesotho: $2.1 \mathrm{~m})$ \\
\hline Durban (Inkosi Albert Luthuli Central Hospital) & KwaZulu-Natal, Tambo District (Eastern Cape) & $13 \mathrm{~m}$ \\
\hline Western Cape Paediatric Cardiac Services & Western Cape, most Eastern Cape, part Northern Cape & $9 \mathrm{~m}$ \\
\hline
\end{tabular}

*Total population: including those covered by medical aid. Population per province derived from: http://www.southafrica.info/about/people/population.htm). 
Arteries (TGA) operated on in each unit is also specifically presented as an indicator of neonatal cardiac services offered in Table 7. Total figures for the country are presented in Table 8.

\section{LIMITATIONS}

The study concentrates on data from large units with established, comprehensive, services. Data of individual paediatric cardiologists who refer to the larger centres for surgery are excluded. Similarly, some adult cardiologists do see paediatric patients, and limited

TABLE 2: Unit coverage - Private hospitals with comprehensive paediatric cardiac services (Together cover medical aid population from throughout South Africa - approximately 5 million population with some patients referred from elsewhere in Africa.).

\begin{tabular}{l|l}
\hline $\begin{array}{l}\text { Christiaan Barnard } \\
\text { Memorial Hospital }\end{array}$ & Mainly Western Cape / Namibia \\
\hline Sunninghill Hospital & $\begin{array}{l}\text { Gauteng / KwaZulu-Natal / Mpumulanga, etc. } \\
\text { sub-Saharan Africa }\end{array}$ \\
\hline Unitas & $\begin{array}{l}\text { Gauteng / Mpumulanga / NorthWest province (few } \\
\text { from surrounding countries) }\end{array}$ \\
\hline
\end{tabular}

* No fixed referral patterns. Patients referred to private centres from throughout the country with general patterns of referral indicated in table. Bloemfontein: private and public sector patients covered by the same unit. surgery for mainly simple cardiac defects may occur in hospitals outside those indicated. Further, within the private sector, because statistics came from various practices, it was not possible in all instances to obtain accurate records of patients seen, and in some cases, estimates were provided by paediatric cardiologists and/or cardiothoracic surgeons from these units. Estimates are indicated in the tables. It is therefore possible that particularly regarding the number of operations and procedures within the private sector, there may be some degree of inaccuracy.

Similarly, within the public sector, limited screening echocardiographic services are provided at some regional hospitals mainly by paediatricians with an interest in paediatric cardiology or occasionally by adult cardiologists. Thus very limited congenital heart surgery as well as valve replacements may have been performed outside the major units mentioned.

A complete separation of public and private patients was not possible as some units, e.g. Bloemfontein, provide a combined service while at Sunninghill Hospital a relatively small number of patients referred from the public sector are operated on under the auspices of the Walter Sisulu Paediatric Cardiac Centre for Africa.

TABLE 3: Medical staff for paediatric cardiac services of both public and private hospitals in South Africa as at December 2008

\begin{tabular}{|c|c|c|c|c|c|c|c|c|c|}
\hline & \multicolumn{5}{|c|}{ Public sector hospitals } & \multicolumn{4}{|c|}{ Private sector } \\
\hline & Johannesburg & Durban & Bloemfontein & Pretoria & WCPCS & SH & $\mathrm{CBMH}$ & Unitas & Other \\
\hline Cardiologists & 4 & I (I vacant) & 2 & 2 & 3 & 6 & 2 & 3 & 1 \\
\hline Trainees & 3 & I (I vacant) & 1 & 1 & 2 & & & 0 & \\
\hline Registrars & 4 & 2 & 1 & 2 & 3 & & & 0 & \\
\hline Surgeons & 2 & 1 & 2 & I (+2) & 2 (I part time) & 4 & 1 & 1 & \\
\hline Anaesthetists & 2 & 1 & 2 & Rotating & 3 (+3 junior) & 4 & 2 & 3 & \\
\hline
\end{tabular}

WCPCS: Western Cape Paediatric Cardiac Services, SH: Sunninghill Hospital, CBMH: Chris Barnard Memorial Hospital.

TABLE 4: Intensive care capacity for post paediatric cardiac surgery patients

\begin{tabular}{|c|c|c|c|c|c|c|c|c|}
\hline & \multicolumn{4}{|c|}{ Public sector hospitals } & & \multicolumn{3}{|c|}{ Private sector } \\
\hline & Johannesburg & Durban & Bloemfontein & Pretoria & WCPCS & $\mathrm{SH}$ & CBMH & Unitas \\
\hline ICU Beds & 2 to 3 & 2 & 2 to 3 & 3 to 5 & $\sim 5 *$ & 17 shared*** & 5 & 3 \\
\hline $\begin{array}{l}\text { Primary } \\
\text { Caregivers }\end{array}$ & $\begin{array}{l}\text { Cardiothoracic } \\
\text { surgeons }\end{array}$ & $\begin{array}{l}\text { Cardiothoracic } \\
\text { surgeons }\end{array}$ & $\begin{array}{l}\text { Cardiothoracic } \\
\text { surgeons }\end{array}$ & $\begin{array}{c}\text { Cardiothoracic } \\
\text { surgeons }\end{array}$ & Paediatricians & Mixed & Anaesthetists & Mixed \\
\hline
\end{tabular}

WCPCS:Western Cape Paediatric Cardiac Services, SH: Sunninghill Hospital, CBMH: Chris Barnard Memorial Hospital. *WCCS - shared with general paediatric ICU. Approximately 5 available for post paediatric cardiac surgery at any one time. **SH - shared with adult cardiac surgery - majority occupied by paediatric patients. 
TABLE 5: Patient load: Number of paediatric cardiac patients seen per centre in 2006

\begin{tabular}{|c|c|c|c|c|c|c|c|c|}
\hline & \multicolumn{3}{|c}{ Public sector hospitals } & & \multicolumn{3}{c|}{ Private sector } \\
\hline & Johannesburg & Durban & Bloemfontein & Pretoria & WCPCS & SH & CBMH & Unitas \\
\hline Total & 3899 & 2200 & 2510 & 2000 & 4360 & 3443 & $*$ & $*$ \\
\hline New & 1917 & 800 & 1233 & 400 & 760 & 1675 & 730 & $*$ \\
\hline
\end{tabular}

WCPCS:Western Cape Paediatric Cardiac Services, SH: Sunninghill Hospital, CBMH: Chris Barnard Memorial Hospital. *Information unavailable as some practices where unable to separate their general paediatriclother patients from paediatric cardiac patients or where unable to provide the relevant information.

TABLE 6: Paediatric cardiology services performed annually in major centres

\begin{tabular}{|l|c|c|c|c|c|c|c|c|}
\hline \hline & \multicolumn{9}{|c|}{ Public sector hospitals } & & \multicolumn{4}{c|}{ Private sector } \\
\hline & Johannesburg & Durban & Bloemfontein & Pretoria & WCPCS & SH & CBMH & Unitas \\
\hline Echo & 3690 & 2300 & 3395 & 1500 & 4500 & 3587 & 1050 & $\sim 1000$ \\
\hline Caths -total & 225 & 180 & 209 & 130 & 350 & 209 & 80 & $*$ \\
\hline Caths-Inter & 85 & 45 & 58 & 30 & 120 & 98 & 25 & $\sim 11$ \\
\hline
\end{tabular}

WCPCS:Western Cape Paediatric Cardiac Services, SH: Sunninghill Hospital, CBMH: Chris Barnard Memorial Hospital. Caths: cardiac catheterisations. Inter: interventions.

*Information not supplied. approximation. Data is for 2006 except where approximations have been supplied.

TABLE 7: Annual paediatric cardiac surgical load for 2006

\begin{tabular}{|c|c|c|c|c|c|c|c|c|}
\hline & \multicolumn{4}{|c|}{ Public sector hospitals } & & \multicolumn{3}{|c|}{ Private sector } \\
\hline & Johannesburg & Durban & Bloemfontein & Pretoria & WCPCS & SH & $\mathrm{CBMH}$ & Unitas \\
\hline CPB & $90-100$ & 100 & 133 & 76 & 140 & 249 & $\sim 80-110$ & $\sim 45$ \\
\hline Closed & $20-30$ & 30 & 22 & 65 & 90 & 68 & $\sim 40-70$ & $\sim 30$ \\
\hline RHD & $15-20$ & 38 & 10 & 15 & 25 & 16 & $<10$ & \\
\hline Waiting list & $>200$ & $\sim 150$ & 26 & nil & $>200$ & $10-20 *$ & & \\
\hline $\begin{array}{l}\text { Simple TGA } \\
\text { operations }\end{array}$ & 5 & 3 & 0 & 3 & 5 & 7 & 3 & 2 \\
\hline
\end{tabular}

WCPCS: Western Cape Paediatric Cardiac Services, SH: Sunninghill Hospital, CBMH: Chris Barnard Memorial Hospital.

CPB: cardiopulmonary bypass. Closed : operations without CPB. RHD: Rheumatic heart disease. TGA:Transposition of great arteries.

*Applies to patients for Walter Sisulu Paediatric Cardiac Centre for Africa. approximate annual numbers

TABLE 8: Summary of personnel, paediatric cardiology and paediatric cardiac surgical procedures performed annually in South Africa

\begin{tabular}{l|c|c|}
\hline & Public sector hospitals & Private sector \\
\hline Paediatric cardiologists & 12 & 12 \\
\hline Paediatric cardiac surgeons & 8 & 5 \\
\hline Cardiology trainees & 8 & - \\
\hline Echocardiograms & $15385+$ & $5637+$ \\
\hline Total cardiac catheterisations & 1100 & $289+$ \\
\hline Interventional cardiac catheterisations & 353 & $\sim 133$ \\
\hline Operations for congenital heart disease & 800 & $\sim 570$ \\
\hline Simple transposition of great arteries operated on in 2006 & 18 & 12 \\
\hline Operations for rheumatic heart disease & 100 & $\sim 20$ \\
\hline
\end{tabular}

Summary for personnel is for end 2008. Other data is annual data for 2006 except where estimates were provided (indicated by ). +indicates where procedures performed in the country as a whole are in excess of the number shown as procedures performed outside the major centres are not included or data from some centres were not supplied. 


\section{DISCUSSION}

A marked disparity exists between the public and private sector services, with regard to interventions offered as well as in terms of trained personnel. Twelve paediatric cardiologists are available countrywide in South Africa serving a medical aid population of approximately five million as well as a relatively small number of patients from elsewhere in Africa.This ratio of paediatric cardiologists to patients is optimal according to international recommendations, exceeding the cardiologist/population ratios of many developed countries. ${ }^{(1)}$ Of concern is that these centres are concentrated in particular geographical areas. The situation within the public sector, however, is very different, with an overall paediatric cardiologists/ population ratio of I: 4.5 million people. In some units, such as those in Pretoria and Durban, this approaches a ratio of I: 10 million people.

Our data suggests that about I 370 patients were operated on for congenital heart disease in 2006. Of these about 800 were in the public sector and 570 in the private sector, with some private sector patients being referred from other countries. Based on demographic studies approximately 4000 children should be operated on annually in South Africa for congenital heart lesions, thus it is evident that less than $40 \%$ of children with congenital heart disease are receiving the care they should be getting. This discrepancy may be due to service deficiencies at multiple levels: the diagnosis of congenital heart disease particularly in the neonate and infant is being missed; paediatric and paediatric cardiac services to evaluate these patients are overwhelmed; and congenital heart surgical services are insufficient and unable to cope with the long waiting lists. Simple transposition of great arteries (TGA) is one of the commonest cyanotic congenital heart conditions presenting in the neonatal period and if left untreated is usually fatal. The number operated on annually in South Africa is an indirect indicator of the adequacy of our service in diagnosing serious congenital heart disease in the neonate: only 30 TGAs were corrected in the country in 2006, 12 of them in the private sector. This is in stark contrast to the 152 simple TGAs having surgical correction over a similar period by the NHS in the United Kingdom. ${ }^{(7)}$ A simple estimate indicates that at least 114 simple TGAs should have been corrected in South Africa in 2006.

\section{CONCLUSION}

Serious deficiencies exist with the paediatric cardiac services offered in the country, particularly by the public health services. The primary concerns are that:

- The infrastructure to detect cardiac conditions in children is not in place and a large number of children are being missed.

- The services to handle even the limited number of patients that are presenting for intervention are grossly inadequate in most centres.

It is clear that the majority of children with cardiac disease are not receiving the care that is required. The resource deficiencies within the service need to be urgently addressed if the needs of this vulnerable population are to be met.

\section{ACKNOWLEDGEMENTS}

Appreciation is expressed to the following who supplied data for the audit:

H. Pribut: Paediatric cardiologist, Christiaan Barnard Memorial Hospital, Cape Town

S.M. Vosloo: Cardiothoracic surgeon, Christiaan Barnard Memorial Hospital, Cape Town

E.L. Colyn: Paediatric cardiologist, Unitas Hospital, Pretoria

J. deVilliers: Cardiothoracic surgeon: Unitas Hospital, Pretoria

P. Colsen: Cardiothoracic surgeon: Sunninghill Hospital, Johannesburg

\section{REFERENCES}

I. Multiple authors. Fifth Report on the provision of services for patients with heart disease. (United Kingdom) Heart 2002;88 (suppl III): iiil liii59.

2. Statistics South Africa. Live births 2005 www.statssa.gov.za (Accessed 18 December 2008).

3. Chang RK, Klitzner TS. Resources, use, and regionalisation of pediatric cardiac services. Curr Opin Cardiol 2003:18(2):98-101.

4. Marijon E, Ou P, Celermajer DS, et al. Prevalence of rheumatic heart disease detected by echocardiographic screening. N Engl J Med. 2007;357(5):470-6.

5. Bongani Mayosi, Kate Robertson, Jimmy Volmink, et al. The Drakensberg Declaration on the Control of Rheumatic Fever and Rheumatic Heart Disease in Africa. S Afr Med J ; 2006 Mar;96(3 Pt 2):246.

6. Warnes CA, Liberthson R, Danielson GK, et al. Task force I:The changing profile of congenital heart disease in adult life. J Am Coll Cardiol 200I Apr;37(5): 1 $170-5$.

7. NHS congenital heart disease website: www.ccad.org.uk (Accessed I8 December 2008). 